\title{
Economic Cost Model of Options to Global Sulphur Cap considering Speed Differentiation
}

\author{
Daozheng Huang $\mathbb{D}^{1}$ and Yimin $\mathrm{Hua}^{2}$ \\ ${ }^{1}$ College of Transport and Communications, Shanghai Maritime University, Shanghai 201306, China \\ ${ }^{2}$ School of Traffic and Transportation, Beijing Jiaotong University, Beijing 100044, China \\ Correspondence should be addressed to Daozheng Huang; dzhuang@shmtu.edu.cn
}

Received 19 July 2021; Accepted 15 January 2022; Published 8 February 2022

Academic Editor: Tingsong Wang

Copyright (c) 2022 Daozheng Huang and Yimin Hua. This is an open access article distributed under the Creative Commons Attribution License, which permits unrestricted use, distribution, and reproduction in any medium, provided the original work is properly cited.

\begin{abstract}
The 2020 global sulphur cap has been implemented to reduce the sulphur emission of the maritime transportation industry. It is a huge challenge for the ship owners to select a proper strategy to comply with the regulation. This study analyzes the economic costs of measures to comply with the sulphur cap including switching to low sulphur fuel oil (LSFO) and scrubbers. Meanwhile, considering the influence of the speed optimization on the voyage cost, an economic cost model of the LSFO method is combined with speed differentiation inside and outside the Sulphur Emission Control Area (SECA). The route from Shanghai to Los Angeles is set as a case study. The optimal speeds inside and outside the SECA are calibrated. Then, the economic costs of both methods are calculated and compared. The results show that the speed differentiation strategy can reduce the economic cost of the LSFO method and thus reduce its cost disadvantage over scrubbers. In addition, a low discount rate would benefit the scrubber option based on sensitivity analysis.
\end{abstract}

\section{Introduction}

The maritime transportation is the primary method to transport strategic materials and products onto land and takes up $90 \%$ load of international trade [1]. However, the emissions from maritime transportation make up most of the air pollution in global ports and sea areas $[2,3]$. To protect the maritime environment, the International Maritime Organization has continuously reached regulations to limit sulphur emissions. The latest 2020 global sulphur cap requires the mass proportion of sulphur in fuel oil used in all vessels not to exceed $0.5 \%$ [4]. The requirement for Sulphur Emission Control Areas (SECAs) is still $0.1 \%$. To meet the new regulation, three options are extensively discussed, including utilizing Low Sulphur Fuel Oil (LSFO), installing scrubbers, and using nonpetroleum-based fuels, such as liquid natural gas (LNG) $[5,6]$. The installation of scrubbers will lead to a huge initial capital cost and the use of LSFO or LNG will significantly increase the operational costs. It is a huge challenge for ship owners to choose the most appropriate method to satisfy the sulphur emission limit at a low economic cost.

Switching from Heavy Sulphur Fuel Oil (HSFO) to LSFO is widely accepted as an attractive option in practice. An important advantage is that it does not need a huge initial investment [7]. Only the engine room of a vessel needs to be appropriately modified to adapt to new fuel oil. Under the new sulphur regulation, LSFO is suitable for the open sea. As for SECAs, Marine Gas Oil (MGO) is required. LSFO is normally more expensive than HSFO, which will thus increase the operational cost of shipping. Another potential disadvantage of using LSFO is that its supply may be uncertain.

Another option is to install an exhaust gas cleaning system, such as a scrubber. It requires huge initial capital cost to buy and install a scrubber, while possibly save money since the operational cost of scrubbers is much less than that of LSFO. A probable shortage of scrubbers is that they clean air emissions at the expense of polluting the sea [8]. 
LNG is a clean fuel, which is not only helpful to reduce sulphur emissions but also beneficial to reduce other kinds of emissions, such as nitrogen oxide and particular materials. However, the economic cost of using LNG is the highest among the three alternatives [6]. Furthermore, the LNG approach also requires a large space which may reduce the volume of cargoes that can be loaded on a vessel. LNG is considered a good option for complying with the IMO's sulphur cap and currently has large advantages for those ships that operate mainly within ECAs. However, as it cannot enable the required IMO's GHG reductions, its role as a marine fuel is likely to be only transitory. Thus, in this paper, LNG is not considered.

All three options outlined can satisfy the revised MARPOL Annex VI regulation [7]. Researchers have conducted studies to compare the alternatives [7-10].

Speed differentiation inside and outside SECAs was proposed by Fagerholt and Psaraftis to maximize daily profits [11]. The speed differentiation strategy means that the vessel runs at a low velocity inside SECAs and a fast velocity outside. Gu and Wallace figured out former literature might overestimate the advantage of scrubbers since speed differentiation is not considered in the LSFO alternative [12]. The speed differentiation significantly impacts the life cycle cost of the LSFO option before 2020. However, under the 2020 sulphur cap, the sulphur emission gap inside and outside the SECAs decreases significantly. How will the speed differentiation affect the comparison of the LSFO method and scrubbers? This research compares the two alternatives considering speed differentiation inside and outside the SECAs under the 2020 sulphur limit cap, so as to help stakeholders make an appropriate decision.

Section 2 reviews the literature about measures to comply with the sulphur limit. Section 3 builds an economic cost model considering speed differentiation for the two alternatives. A case study is illustrated to verify the model in Section 4. The conclusions are given in Section 5.

\section{Literature Review}

Economic cost comparison of different alternatives to comply with the sulphur emission cap is widely discussed in historical literature $[6,9]$. Normally, the fuel cost was calculated according to an economic speed all along the shipping route. In 2015, Fagerholt and Psaraftis suggested two speeds in and out of ECAs and found the best point to move into an ECA [11]. Speed optimization is a classical problem in shipping planning and operation management initially to make maximized profit or reach minimum fuel cost [13]. As environmental issues draw more and more attention, speed reduction is utilized to reduce emissions [14]. Given the different sulphur limit regulations in and out of the SECAs, the speed optimization strategy was considered in the LSFO method by using fast speed outside the SECAs and low speed within the SECAs [15]. Zis et al. proposed a linear programming model to solve the speed optimization problem on a shipping route including legs within SECAs of both the US and Europe [16]. Fan and Gu considered speed differentiation with different sulphur limit scenarios inside and outside Chinese SECAs to compare the LSFO method with scrubber systems and concluded that the scrubber option was an effective option [17].

After January 2020, the sulphur emission limit is much stricter. The sulphur limit in the open sea is decreased to $0.5 \% \mathrm{~m} / \mathrm{m}$, the same as the criteria inside Chinese SECAs. Speed optimization issue exists only between the open sea and the northern Europe, North America, and other US SECAs. As the sulphur emission gap in and outside the ECAs decreases, the influence of the speed differentiation strategy would also decrease. Nevertheless, to what extend will the influence decrease remains to be discussed.

\section{Economic Cost Model considering Speed Differentiation}

Based on the lifespan cost analysis model in [6], an adapted economic cost model of the LSFO method and scrubbers of second-hand container ships is established considering the speed difference strategy.

The implementation of the sulphur emission limit in 2020 will undoubtedly increase the fuel and equipment costs of shipping companies. The comparison of the lifespan costs of the LSFO method and the scrubber method combined with the speed differentiation model can provide reference for liner shipping companies under the strict sulphur limit.

3.1. Assumptions. Three assumptions are made as follows to build the economic cost analysis model considering speed differentiation:

The alteration of the ship's engine room or installation of a scrubber on the ship's loading capacity does not decrease the loaded cargoes, which means that the revenue of the ship will remain the same. Therefore, the alternative with the minimum cost is the most profitable one.

For the LSFO method, in order to meet the sulphur emission limit, ships should use MGO with $0.1 \%$ sulphur content when sailing within SECA and LSFO with $0.5 \%$ sulphur content when sailing outside SECA. In the scrubber option, ships sailing inside and outside the SECA could still use HSFO containing 3.5\% sulphur.

Fuel consumption is not considered to vary with the fuel type used.

3.2. Preparations. Table 1 defines the variables and terminologies used in this model.

3.3. NPV of Economic Cost. The basic NPV model of total economic cost in $n$ years is represented by (1). The details of (1) can be found in [6]:

$$
P V=C^{0}+(A+M)\left[\frac{\left((1+i)^{n}-1\right)}{\left(i(1+i)^{n}\right)}\right]-S\left[\frac{1}{\left((1+i)^{n}\right)}\right] \text {. }
$$


TABle 1: Notations.

\begin{tabular}{|c|c|}
\hline \multicolumn{2}{|c|}{ General parameters of the model } \\
\hline$D_{S}$ & Distance within SECAs (n mile) \\
\hline$D_{N}$ & Distance outside SECAs (n mile) \\
\hline$V$ & Sailing speed $(\mathrm{knot})$ \\
\hline$F$ & Conversion factor between speed and fuel consumption \\
\hline$f_{w}$ & Berthing day fuel consumption per round voyage (ton) \\
\hline$r$ & Freight rate per container $(\$)$ \\
\hline$a$ & The capacity utility rate \\
\hline$R$ & Revenue from the sailing routes $(\$)$ \\
\hline Q & Container capacity of vessels (TEU) \\
\hline$m$ & The number of round voyages per year \\
\hline $\mathrm{P}_{\text {LSFO }}$ & Price of LSFO with a sulphur content of $0.5 \%$ (\$/ton) \\
\hline $\mathrm{P}_{\mathrm{MGO}}$ & Price of MGO with a sulphur content of $0.1 \%$ (\$/ton) \\
\hline $\mathrm{P}_{\mathrm{HSFO}}$ & Price of HSFO with a sulphur content of $3.5 \%$ ( $\$ /$ ton) \\
\hline$i$ & Discount rate \\
\hline$n$ & Total period (year) \\
\hline$C^{0}$ & The initial investment cost $(\$)$ \\
\hline$A$ & Annual operational expenditures (\$/year) \\
\hline$M$ & Annual maintenance cost $(\$ /$ year $)$ \\
\hline$S$ & Salvage value at the end of the useful economic of the equipment (\$) \\
\hline PV & Present value (\$) \\
\hline \multicolumn{2}{|c|}{ Parameters of the LSFO method } \\
\hline $\mathrm{C}_{\text {LSFO }}^{0}$ & The initial cost of purchase and installation of fuel converter (\$) \\
\hline $\mathrm{A}_{\text {LSFO }}$ & Annual operational expenditures of fuel converter (\$/year) \\
\hline $\mathrm{m}_{\text {LSFO }}$ & The number of round voyages per year for the LSFO method \\
\hline $\mathrm{M}_{\mathrm{LSFO}}$ & Annual maintenance cost of fuel converter (\$/year) \\
\hline$f_{\mathrm{S}}$ & MGO consumption per round voyage within SECAs (ton) \\
\hline$f_{\mathrm{N}}$ & LSFO consumption per round voyage outside SECAs (ton) \\
\hline $\mathrm{f}_{\mathrm{LSFO}}$ & Fuel consumed per round voyage (ton) \\
\hline $\mathrm{F}_{\mathrm{LSFO}}$ & Annual cost of fuel consumption (\$/year) \\
\hline $\mathrm{S}_{\mathrm{LSFO}}$ & Salvage value of the fuel converter at the end of the time period $(\$)$ \\
\hline \multicolumn{2}{|c|}{ Parameters of the use of a scrubber } \\
\hline $\mathrm{C}_{\text {scrubber }}^{0}$ & The initial cost of purchase and installation of a scrubber (\$) \\
\hline $\mathrm{A}_{\text {scrubber }}$ & Annual operation expenditures of scrubber systems (\$/year) \\
\hline $\mathrm{mscm}_{\text {scrubber }}$ & The number of round voyages per year for the scrubber method \\
\hline $\mathrm{mscM}_{\text {scrubber }}$ & Annual maintenance cost of scrubber systems (\$/year) \\
\hline $\mathrm{f}_{\text {scrubber }}$ & Fuel consumed per round voyage (ton) \\
\hline $\mathrm{F}_{\text {scrubber }}$ & Annual cost of fuel consumption (\$/year) \\
\hline $\mathrm{E}_{\text {scrubber }}$ & Annual cost of equipment operation (\$/year) \\
\hline $\mathrm{S}_{\text {scrubber }}$ & Salvage value of the scrubber at the end of its the time period (\$) \\
\hline \multicolumn{2}{|c|}{ General variables of the model } \\
\hline$V_{\mathrm{S}}$ & Sailing speed inside SECAs (knot) \\
\hline$V_{\mathrm{N}}$ & Sailing speed outside SECAs (knot) \\
\hline$T_{\mathrm{S}}$ & Travelling time inside SECAs (day) \\
\hline$T_{\mathrm{N}}$ & Travelling time outside SECAs (day) \\
\hline
\end{tabular}

3.4. Economic Cost of the Two Options. Equation (1) is a general formula and the variable $A$ has different specific meanings in the two options.

3.4.1. Cost of the LSFO Method. In the LSFO method, the annual cost of fuel consumption accounts for most of the annual operating cost $A$. Thus, $A$ is represented by annual fuel consumption cost as

$$
A_{\mathrm{LSFO}}=F_{\mathrm{LSFO}} .
$$

In the LSFO method, the fuel consumption consists of two parts, MGO consumption in SECAs and LSFO consumption out of SECAs. Based on the explanation of variables in Table 1, the consumption of MGO in a voyage includes the MGO consumed in SECAs and at berth time. The cost of MGO consumed in SECAs is calculated as $f_{\mathrm{S}}$ times $P_{M G O}$, while the cost of LSFO out of SECAs is calculated as $f_{N}$ times $P_{L S F O}$. The annual fuel consumption cost equals the number of voyages multiplied by the sum of fuel consumption cost of MGO and LSFO per voyage, as shown in the following equation: 


$$
F_{\mathrm{LSFO}}=\left(P_{\mathrm{MGO}} f_{S}+P_{\mathrm{LSFO}} f_{N}+P_{\mathrm{MGO}} f_{w}\right) \times m_{\mathrm{LSFO}} \text {. }
$$

The relationship between power, speed, and fuel consumption is as

$$
N_{e}=\frac{\Delta^{2 / 3} V^{3}}{C_{e}}
$$

where $N_{e}$ represents the power of the main engine of the ship, $\Delta$ means the tonnage of the ship, and $C_{e}$ is the naval constant. According to the relationship between $N_{e}$ and $V$, it can be concluded that there is also a relatively complex quantitative relationship between $V$ and fuel consumption. The complicated mathematical relationship can be simplified through regression analysis, and it can be concluded that fuel consumption is proportional to the cubic power of speed. In this way, $f_{S}$ and $f_{N}$ can be obtained according to equations (5) and (6):

$$
\begin{gathered}
f_{S}=F \times V_{S}^{3} \times\left(\frac{D_{S}}{V_{S}}\right), \\
f_{N}=F \times V_{N}^{3} \times\left(\frac{D_{N}}{V_{N}}\right) .
\end{gathered}
$$

Thus, incorporating (2) and (3) into equation (1), equation (7) is obtained to calculate the economic cost of the LSFO method:

$$
P V_{\mathrm{LSFO}}=C_{\mathrm{LSFO}}^{0}+\left[\left(P_{\mathrm{MGO}} f_{S}+P_{\mathrm{LSFO}} f_{N}+P_{\mathrm{MGO}} f_{w}\right) \times m_{\mathrm{LSFO}}+M_{\mathrm{LSFO}}\right]\left[\frac{\left((1+i)^{n}-1\right)}{i(1+i)^{n}}\right]-S_{\mathrm{LSFO}}\left[\frac{1}{(1+i)^{n}}\right]
$$

3.4.2. Cost of Scrubbers. In the scrubber option, the annual operational cost is different from that of the LSFO method. The daily operation of scrubbers needs reagent, which causes an annual cost of scrubber operation notated as $E_{\text {scrubber. }}$ So, $A_{\text {scrubber }}$ is the sum of $F_{\text {scrubber }}$ and $E_{\text {scrubber }}$ as follows:

$$
A_{\text {scrubber }}=F_{\text {scrubber }}+E_{\text {scrubber }} \text {. }
$$

The fuel consumption cost of scrubbers per voyage equals to the volume of HSFO times the price of HSFO. Multiplied by the number of voyages in one year, the annual fuel consumption cost can be calculated as follows:

$$
F_{\text {scrubber }}=P_{\text {HSFO }} \times f_{\text {scrubber }} \times m_{\text {scrubber }} .
$$

Incorporating (8) and (9) into equation (1), (10) is obtained:

$$
\begin{aligned}
& P V_{\text {scrubber }}=C_{\text {scrubber }}^{0}+\left(P_{\mathrm{HSFO}} \times f_{\text {scrubber }} \times m_{\text {scrubber }}+E_{\text {scrubber }}+M_{\text {scrubber }}\right)\left[\frac{\left((1+i)^{n}-1\right)}{\left(i(1+i)^{n}\right)}\right]-S_{\text {scrubber }}\left[\frac{1}{(1+i)^{n}}\right] . \\
& f_{\mathrm{LSFO}}=F V_{S}^{2} D_{S} P_{\mathrm{MGO}}+F V_{N}^{2} D_{N} P_{\mathrm{LSFO}} \cdot
\end{aligned}
$$
model means determining the optimal speeds of a vessel sailing inside and outside the SECA by taking into account the different prices of LSFO and MGO used in the LSFO alternative. Meanwhile, it is assumed that the fuel consumption of a vessel is linear to the cubic power of the speed. Some general parameters and variables of the model to be utilized in the following analysis are listed in Table 1.

The cost of fuel consumed inside the SECA is shown in the following equation:

$$
24 \times F V_{S}^{3} T_{S} P_{\mathrm{MGO}}=F V_{S}^{2} D_{S} P_{\mathrm{MGO}} .
$$

The cost of fuel consumption outside the SECA is similar to that inside the SECA. Thus, the total fuel cost can be obtained through the following equation:
The revenue per sailing route can be expressed as

$$
R=a \times r \times Q .
$$

Our target is to make the maximum profit per voyage as

$$
\begin{aligned}
\max z & =\frac{\left(R-F V_{S}^{2} D_{S} P_{\mathrm{MGO}}-F V_{N}^{2} D_{N} P_{\mathrm{LSFO}}\right)}{\left(T_{S}+T_{N}\right)} \\
& =\frac{\left(R-F V_{S}^{2} D_{S} P_{M G O}-F V_{N}^{2} D_{N} P_{\mathrm{LSFO}}\right)}{\left(D_{S} / V_{S}+D_{N} / V_{N}\right)} .
\end{aligned}
$$

According to the first-order necessary optimal condition, we have (15) and (16): 
TABLE 2: Input and intermediate data regardless of the speed differentiation model.

\begin{tabular}{|c|c|}
\hline \multicolumn{2}{|c|}{ Input data } \\
\hline$V$ & 18 knots east and 20 knots west \\
\hline$m$ & 6 \\
\hline$f_{s}$ & 84.5 tons/round voyage \\
\hline$f_{n}$ & 2915.5 tons/round voyage \\
\hline$f_{\text {scrubber }}$ & 3000 tons/round voyage \\
\hline$n$ & 10 \\
\hline$i$ & $5 \%$ \\
\hline$P_{L S F O}$ & $\$ 547 /$ ton \\
\hline$P_{M G O}$ & $\$ 585 /$ ton \\
\hline$P_{H S F O}$ & $\$ 354 /$ ton \\
\hline$C^{0}{ }_{L S F O}$ & $\$ 126,000$ \\
\hline$C_{\text {scrubber }}^{0}$ & $\$ 2,400,000$ \\
\hline$E_{\text {scrubber }}$ & $3 \%$ of annual fuel consumption cost \\
\hline$M$ & $1 \%$ of the initial capital cost \\
\hline$S$ & $5 \%$ of the initial capital cost \\
\hline \multicolumn{2}{|c|}{ Intermediate data } \\
\hline$P V_{L S F O}$ & $\$ 7.63 \times 10^{7}$ \\
\hline$P V_{\text {scrubber }}$ & $\$ 5.32 \times 10^{7}$ \\
\hline
\end{tabular}

TABLE 3: Input and intermediate data of the speed differentiation model.

\begin{tabular}{|c|c|}
\hline \multicolumn{2}{|c|}{ Input data of the speed differentiation analysis } \\
\hline$P_{L S F O}$ & $\$ 547 /$ ton \\
\hline$P_{M G O}$ & $\$ 585 /$ ton \\
\hline$D_{N}$ & $5562 \mathrm{n}$ mile \\
\hline$D_{S}$ & $200 n$ mile \\
\hline$F$ & 0.014 \\
\hline$r$ & $\$ 2661$ \\
\hline$a$ & $90 \%$ \\
\hline Q & $10000 \mathrm{TEU}$ \\
\hline \multicolumn{2}{|c|}{ Intermediate data } \\
\hline$R$ & $\$ 23949000$ \\
\hline
\end{tabular}

TABle 4: Output data of the speed differentiation model.

\begin{tabular}{lr}
\hline & Output data \\
\hline$T_{N}$ & 34.5 days/voyage \\
$T_{S}$ & 1.3 days/voyage \\
$V_{N}$ & $13.15 \mathrm{knots}$ \\
$V_{S}$ & 13.45 knots \\
\hline
\end{tabular}

$$
\begin{aligned}
& \frac{\partial z}{\partial_{V_{S}}}=-\frac{D_{S}\left(F D_{S} P_{\mathrm{MGO}} V_{S}^{2}+F D_{N} P_{\mathrm{LSFO}} V_{N}^{2}\right)}{V_{S}^{2}\left(D_{S} / V_{S}+D_{N} / V_{N}\right)}-\frac{2 F D_{S} P_{\mathrm{MGO}} V_{S}}{D_{S} / V_{S}+D_{N} / V_{N}}=0, \\
& \frac{\partial z}{\partial_{V_{N}}}=-\frac{D_{N}\left(F D_{S} P_{\mathrm{MGO}} V_{S}^{2}+F D_{N} P_{\mathrm{LSFO}} V_{N}^{2}\right)}{V_{N}^{2}\left(D_{S} / V_{S}+D_{N} / V_{N}\right)}-\frac{2 F D_{N} P_{\mathrm{LSFO}} V_{N}}{D_{S} / V_{S}+D_{N} / V_{N}}=0 .
\end{aligned}
$$

\section{Test Case}

In the test case, a 10000TEU container ship that sails from Shanghai to Los Angeles is selected as a case study vessel. The data of the ship and route are provided by COSCO Shipping Lines. The data on the scrubber are collected from Clarkson [18]. All the input data and intermediate are shown in
Table 2. By substituting the actual data into the calculation in Section 3.3, it can be concluded that, before speed optimization, $P V_{L S F O}$ is $\$ 7.63 \times 10^{7}$ and $P V_{\text {scrubber }}$ is $\$ 5.32 \times 10^{7}$.

4.1. Result of the Speed Differentiation Model. The ship's particulars as well as voyage parameters are shown in 
TABle 5: Parameter data and economic cost of the LSFO option.

\begin{tabular}{|c|c|}
\hline \multicolumn{2}{|c|}{ Input data } \\
\hline$P_{L S F O}$ & $\$ 547 /$ ton \\
\hline$P_{M G O}$ & $\$ 585 /$ ton \\
\hline$V_{S}$ & 13.15 knots \\
\hline$V_{N}$ & 13.45 knots \\
\hline$F$ & 0.014 \\
\hline$m_{L S F O}$ & 6 \\
\hline$C_{L S F O}^{0}$ & $\$ 126,000$ \\
\hline$f_{w}$ & 566.5 tons/voyage \\
\hline$n$ & 10 \\
\hline$i$ & $5 \%$ \\
\hline \multicolumn{2}{|c|}{ Intermediate data } \\
\hline$F_{L S F O}$ & $\$ 5,982,754$ \\
\hline$M_{L S F O}$ & $\$ 1260$ \\
\hline$S_{L S F O}$ & $\$ 6300$ \\
\hline$P V_{L S F O}$ & $\$ 4.63 \times 10^{7}$ \\
\hline
\end{tabular}

TABle 6: Parameter data and economic cost of the scrubber option.

\begin{tabular}{|c|c|}
\hline \multicolumn{2}{|c|}{ Input data } \\
\hline$P_{H S F O}$ & $\$ 354 /$ ton \\
\hline$V$ & 13.58 knots \\
\hline$F$ & 0.014 \\
\hline$m_{\text {scrubber }}$ & 6 \\
\hline$C_{\text {scrubber }}$ & $\$ 2,400,000$ \\
\hline$f_{w}$ & 566.5 tons/voyage \\
\hline$n$ & 10 \\
\hline$i$ & $5 \%$ \\
\hline \multicolumn{2}{|c|}{ Intermediate data } \\
\hline$F_{\text {scrubber }}$ & $\$ 3,780,179$ \\
\hline$M_{\text {scrubber }}$ & $\$ 24,000$ \\
\hline$S_{\text {scrubber }}$ & $\$ 120,000$ \\
\hline$E_{\text {scrubber }}$ & $\$ 113,405$ \\
\hline$P V_{\text {scrubber }}$ & $\$ 3.26 \times 10^{7}$ \\
\hline
\end{tabular}

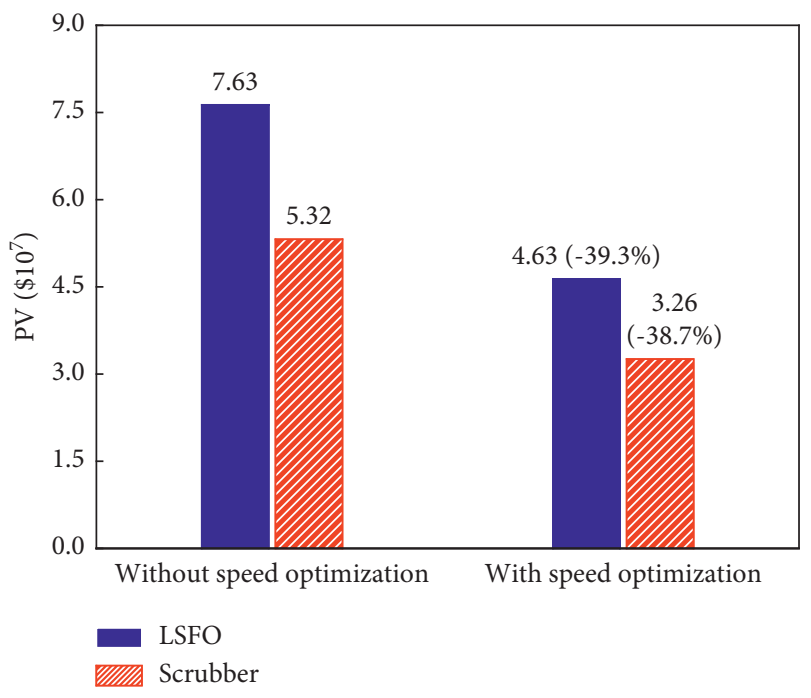

Figure 1: The economic costs of alternatives with and without speed optimization. 
TABle 7: Comparison of the two alternatives under different discount rates.

\begin{tabular}{lcccccc}
\hline $\begin{array}{l}\text { Discount } \\
\text { rate }\end{array}$ & $\begin{array}{c}\text { WSFO }\left(P_{L S F O}: \$ 547 /\right. \\
\text { ton })\left(P_{M G O}: \$ 585 /\right. \\
\text { ton })\end{array}$ & $\begin{array}{c}\text { Scrubber } \\
(\$ 354 / \text { ton })\end{array}$ & $\begin{array}{c}\text { Lifespan cost difference } \\
\text { between LSFO and } \\
\text { scrubber }\end{array}$ & $\begin{array}{c}\text { LSFO }\left(P_{L S F O}: \$ 547 /\right. \\
\text { ton })\left(P_{M G O}: \$ 585 /\right. \\
\text { ton })\end{array}$ & $\begin{array}{c}\text { Scrubber } \\
(\$ 354 / \text { ton })\end{array}$ & $\begin{array}{c}\text { Lifespan cost difference } \\
\text { between LSFO and } \\
\text { scrubber }\end{array}$ \\
\hline$i=1 \%$ & $\$ 9.36 \times 10^{7}$ & $\$ 6.47 \times 10^{7}$ & $\$ 2.89 \times 10^{7}$ & $\$ 5.68 \times 10^{7}$ & $\$ 3.94 \times 10^{7}$ & $\$ 1.74 \times 10^{7}$ \\
$i=5 \%$ & $\$ 7.63 \times 10^{7}$ & $\$ 5.32 \times 10^{7}$ & $\$ 2.31 \times 10^{7}$ & $\$ 4.63 \times 10^{7}$ & $\$ 3.26 \times 10^{7}$ & $\$ 1.3710^{7}$ \\
$i=10 \%$ & $\$ 6.07 \times 10^{7}$ & $\$ 4.28 \times 10^{7}$ & $\$ 1.79 \times 10^{7}$ & $\$ 3.69 \times 10^{7}$ & $\$ 2.64 \times 10^{7}$ & $\$ 1.05 \times 10^{7}$ \\
\hline
\end{tabular}

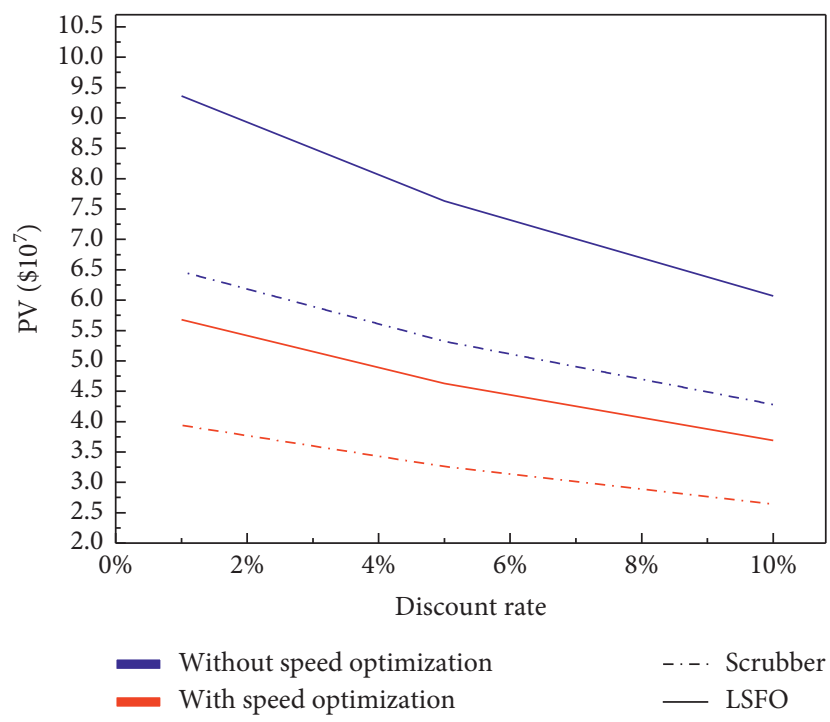

Figure 2: The economic cost analysis of discount rate fluctuations.

Table 3. With the data of parameters, 12 and (13) are solved utilizing Matlab software. $V_{S}$ and $V_{N}$ are figured out as 13.15 and 13.45 knots, respectively, as listed in Table 4 .

4.2. NPV of Two Alternatives considering Speed Differentiation. Substituting the values of $V_{S}$ and $V_{N}$ into (3), the fuel consumption per voyage $\left(f_{L S F O}\right)$ is calculated as $\$ 665,714$. Considering that the vessel makes six round voyages a year and its fuel consumption cost $\left(f_{w} \times P_{\mathrm{MGO}}\right)$ during berthing days, its annual fuel consumption $\left(F_{L S F O}\right)$ is $\$ 5,982,754$.

According to the input data of the LSFO alternative in Table 5, $P V_{L S F O}$ is calculated.

The speed differentiation model will increase the voyage time. In order to make the scrubber more comparable to the LSFO method, we assume that the sailing time of the two alternatives is the same as 52.4 days, of which the sailing time is 35.8 days and the berthing time is 16.6 days. In this case, the sailing speed of the vessel installing scrubbers is 13.43 knots. It is gained by the total voyage distance $11524 \mathrm{n}$ mile $\left(\left(D_{S}+D_{N}\right) \times 2\right)$ divided by the voyage time 35.8 days and then divided by 24 . The fuel cost of using scrubbers is calculated as $\$ 3,780,179$ through $F \times\left(D_{S}+D_{N}\right) \times V^{2} \times P_{\mathrm{HSFO}}$. Then, $P V_{\text {scrubber }}$ is shown in Table 6 .

The economic costs of the two alternatives with and without speed differentiation are compared in Figure 1. As for the scrubber method, the speeds of the ship sailing inside and outside the SECA are the same. In order to make the scrubber method have the same voyage time as the LSFO method with speed differentiation, the speed of vessels using scrubbers is also changed to be 13.58 knots since the sailing distance is constant. Figure 1 indicates that when speed differentiation is considered, both alternatives have significant cost savings. For the LSFO method, the cost savings is larger.

4.3. Scenario Analysis of the Discount Rate. The economic cost of the two alternatives is analyzed under different discount rates. At any discount rate, the economic cost of the two alternatives with speed optimization is much lower than that without speed optimization, as shown in Table 7 and Figure 2. In addition, the LSFO method with speed optimization has a significant cost advantage over scrubbers without speed optimization. The advantage of scrubbers decreases as the discount rate increases. It means that the easier to obtain capital, the more likely to choose a scrubber. Moreover, at any discount rate, the cost gap between the two alternatives considering speed differentiation is smaller than that when speed optimization is not considered.

Meanwhile, when $P_{M G O}$ is $\$ 585$ per ton and $P_{L S F O}$ is $\$ 547$ per ton, if $P_{H S F O}$ is adjusted to $\$ 516$ per ton, the cost of LSFO alternative under speed optimization is the same as the economic cost of the scrubber option. 


\section{Conclusions}

This research assesses the economic costs of two main sulphur limit compliance options considering speed differentiation. The speed differentiation model is combined with the NPV model. The result shows that the speed differentiation method is effective to reduce the total cost of the LSFO method, which makes the LSFO method perform better. Additionally, the sensitivity analysis of the discount rate is considered in our paper. As the discount rate increases, the cost gap between the use of a scrubber and the LSFO alternative gradually decreases.

The weakness of this research is that since the calculation of optimal speeds inside and outside the SECAs depends on the fuel price, it becomes difficult to calculate the price gap between HSFO and LSFO/MGO when the total cost of the two alternatives is the same.

\section{Data Availability}

The data used to support the findings of the study can be obtained from the corresponding author upon request.

\section{Conflicts of Interest}

The authors declare that they have no conflicts of interest.

\section{Authors' Contributions}

H.D.Z. conceptualized the study; H.Y.M. and H.D.Z. developed the methodology; H.Y.M. helped with software; H.D.Z. and H.Y.M. validated the study; H.D.Z. carried out formal analysis; H.D.Z. investigated the study; H.D.Z. helped with resources; H.Y.M. curated data; H.Y.M. and H.D.Z. wrote and prepared the original draft; H.D.Z. reviewed and edited the manuscript; H.D.Z. supervised the study; H.D.Z. carried out funding acquisition. All authors have read and agreed to the published version of the manuscript.

\section{Acknowledgments}

This research was funded by MOE (Ministry of Education in China) Liberal Arts and Social Sciences Foundation (Grant no. 19YJCGJW003). The APC was also funded by this grant.

\section{References}

[1] D. Huang, S. Loughney, and J. Wang, "Identification of China's strategic transport passages in the context of the belt and road initiative," Maritime Policy \& Management, pp. 1-26, 2021.

[2] C. A. Kontovas, "Integration of air quality and climate change policies in shipping: the case of sulphur emissions regulation," Marine Policy, vol. 113, Article ID 103815, 2020.

[3] L. Fan and L. Huang, "Analysis of the incentive for slow steaming in Chinese sulfur emission control areas," Transportation Research Record: Journal of the Transportation Research Board, vol. 2673, no. 3, pp. 165-175, 2019.

[4] Marine Environment Protection Committee (Mepc), "Marine Environment Protection Committee (Mepc)," 2019, https:// www.marineinsight.com/maritime-law/the-marineenvironment-protection-committee-mepc-at-a-glance.

[5] T. Solakivi, S. Laari, T. Kiiski, J. Töyli, and L. Ojala, "How shipowners have adapted to sulphur regulations - evidence from Finnish seaborne trade," Case Studies on Transport Policy, vol. 7, no. 2, pp. 338-345, 2019.

[6] D. Huang, Y. Hua, S. Loughney, E. Blanco-Davis, and J. Wang, "Lifespan cost analysis of alternatives to global sulphur emission limit with uncertainties," Proceedings of the Institution of Mechanical Engineers - Part M: Journal of Engineering for the Maritime Environment, vol. 235, no. 4, pp. 921-930, 2021.

[7] R. Bergqvist, M. Turesson, and A. Weddmark, "Sulphur emission control areas and transport strategies: the case of Sweden and the forest industry," Eur. Transport Res. Rev, vol. 7, pp. 1-15, 2015.

[8] P. Serra and G. Fancello, “Towards the IMO's GHG goals: a critical overview of the perspectives and challenges of the main options for decarbonizing international shipping," Sustainability, vol. 12 , no. 8, p. 3220, 2020.

[9] S. A. Mohseni, E. V. Hassel, C. Sys, and T. Vanelslander, "Economic evaluation of alternative technologies to mitigate Sulphur emissions in maritime container transport from both the vessel owner and shipper perspective," Journal of Shipping and Trade, vol. 4, 2019.

[10] T. P. V. Zis, K. Cullinane, and S. Ricci, "Economic and environmental impacts of scrubbers investments in shipping: a multi-sectoral analysis," Maritime Policy \& Management, pp. 1-19, 2021.

[11] K. Fagerholt and H. N. Psaraftis, "On two speed optimization problems for ships that sail in and out of emission control areas," Transportation Research Part D: Transport and Environment, vol. 39, pp. 56-64, 2015.

[12] Y. Gu and S. W. Wallace, "Scrubber: a potentially overestimated compliance method for the Emission Control Areas," Transportation Research Part D: Transport and Environment, vol. 55, pp. 51-66, 2017.

[13] D. Ronen, "The effect of oil price on the optimal speed of ships," Journal of the Operational Research Society, vol. 33, no. 11, pp. 1035-1040, 1982.

[14] J. J. Corbett, H. Wang, and J. J. Winebrake, “The effectiveness and costs of speed reductions on emissions from international shipping," Transportation Research Part D: Transport and Environment, vol. 14, no. 8, pp. 593-598, 2009.

[15] M. Doudnikoff and R. Lacoste, "Effect of a speed reduction of containerships in response to higher energy costs in Sulphur Emission Control Areas," Transportation Research Part D: Transport and Environment, vol. 28, pp. 51-61, 2014.

[16] T. Zis, R. J. North, P. Angeloudis, W. Y. Ochieng, and M. G. H. Bell, "Environmental balance of shipping emissions reduction strategies," Transportation Research Record: Journal of the Transportation Research Board, vol. 2479, no. 1, pp. 25-33, 2015.

[17] L. Fan and B. Gu, "Impacts of the increasingly strict Sulfur limit on compliance option choices: the case study of Chinese SECA," Sustainability, vol. 12, pp. 1-20, 2019.

[18] C. Clarkson, "Research Services," 2020, https://www. clarksons.com/services/research/shipping-and-trade. 